\title{
Interpretation of British experts' illustrations of fetal heart rate (FHR) decelerations by Consultant Obstetricians, registrars and midwives: A prospective study-Reasons for major disagreement with experts and implications for clinical practice*
}

\author{
Shashikant L. Sholapurkar \\ Department of Obstetrics and Gynaecology, Royal United Hospital NHS Trust, Bath, UK \\ Email: s.sholapurkar@nhs.net
}

Received 24 May 2013; revised 28 June 2013; accepted 7 July 2013

Copyright (C) 2013 Shashikant L. Sholapurkar. This is an open access article distributed under the Creative Commons Attribution License, which permits unrestricted use, distribution, and reproduction in any medium, provided the original work is properly cited.

\begin{abstract}
Objective: To test the reproducibility of British experts' (eFM, K2MS, Gibb and Arulkumaran) [1-3] illustrations of fetal heart rate (FHR) decelerations by trained British Obstetricians and midwives. To analyze reasons for any discrepancies by examining factors relating to the participants, British experts' descriptions and NICE guidelines [4]. Design: Prospective observational study. Setting: National Health Service (NHS) Hospitals. Participants: 38 Obstetric Consultants, 49 registrars and 45 midwives. Methods: Printed questionnaire. Statistical Analysis: Fisher's Exact test. Results: This largest study of its kind showed almost unbelievably high disconnect between CTG interpretation by experts and participants. $98 \%$ $100 \%$ midwives, $80 \%$ - $100 \%$ Registrars and $74 \%$ $100 \%$ Consultants categorized FHR decelerations differently from the five experts' illustrations/interpretations $(p<0.0001)$. Remarkably, the three experts' illustrations of early (supposedly most benign) decelerations were classed as atypical variable by $56 \%$ Consultants, $78 \%$ Registrars and $99 \%$ midwives and the CTGs as pathological by $85 \%$ of the participants. Conclusions: The high degree of disagreement with the experts' illustrations $(p<0.0001)$ did not appear to be due to participant factors. The immediate reasons seemed to be the conflicting illustrations
\end{abstract}

\footnotetext{
*Competing interests: The author has no conflict of interest or funding to declare. Most of the concepts in this paper were previously submitted to relevant guideline group in the form of a detailed document with supporting illustrations and references but no explanation or rebuttal was received. The concepts presented are personal opinion only and do not necessarily reflect practice.
}

and heterogeneity of experts' descriptions. But most importantly, these appeared to stem from non-standardized ambiguous definitions of FHR decelerations and many intrinsic systemic flaws in the current NICE guidelines [4]. The NICE concept of "true uniform” (identical) early and late decelerations seems biologically implausible (a myth) and no examples can be found. Another myth seems to be that early and late decelerations should be gradual. Only very shallow decelerations will look "gradual" on the British CTG. These systemic flaws lead to dysfunctional CTG interpretation increasing intervention as well as impairing diagnosis of fetal hypoxemia. This is because the vast majority of FHR decelerations fall in a single heterogeneous "variable" group with many further classed as "atypical" (pathological) based on disproven and discredited criteria [5-7]. There is increasing evidence in USA that a system with variable decelerations as the majority is clinically unhelpful because of loss of information [5-9]. In the interest of patient care and safety, open debate is necessary regarding a better way forward. Classification of FHR decelerations based primarily and solely on time relationship to contractions appears more scientific and clinically useful.

Keywords: Fetal Heart Rate Decelerations; Electronic Fetal Monitoring; Cardiotocograph; Intrapartum Monitoring

\section{INTRODUCTION}

Electronic fetal monitoring (EFM) is one of the com- 
monest medical procedures in the developed world. Reliable and clinically useful interpretation of intrapartum EFM is of paramount importance to prevent fetal hypoxemia/acidemia as well as to avoid unnecessary intervention. Secondly, the compensation claims for birth asphyxia account for up to $50 \%$ of the NHS litigation bill in UK [10]. The NHS in England paid out £3.1 billion for claims linked to maternity care in the past decadethe most for any specialty-mainly for cerebral palsy and errors in interpretation of cardiotocographs (CTG) [11]. Fetal heart rate (FHR) decelerations are the most common deviant feature on CTG associated with fetal hypoxemia often in the absence of FHR baseline abnormalities. Thus, FHR decelerations are the main determinants of classification into the 3 tier systems of CTG interpretation $[5,12,13]$. Hence, the clinical reliability and usefulness of 3 tier systems will to a large extent depend on standardized, unambiguous and scientifically robust definitions of FHR decelerations [12,14-16]. The current British definitions of decelerations were first introduced in the Royal College of Obstetricians and Gynaecologists (RCOG) guidelines of 2001 (personal correspondence with National Institute for Health and Clinical Excellence-NICE) [4,17]. In its brief guidelines on EFM, NICE has not repeated the definitions of FHR decalerations but the RCOG (2001) guidelines have been taken off-line. Because of the lack of easy access to these definitions, British Obstetricians and midwives interpret FHR decelerations based on the descriptions by a few expert groups and the rigorous mandatory training they undergo at least yearly. There seems to have been a major change in interpretation of FHR decelerations since NICE (2007) guidelines which state that "true uniform" early decalerations (head compression-a universal phenomenon in labor) are very rare and most decelerations in labor are variable (cord compression) [4], which seems counterintuitive. Also, this concept seems alien to established British practice over many decades before 2007. An opinion survey of 40 British Consultant Obstetricians revealed that "early" decelerations were the majority (more than 50\%) before 2007 but this was expected to change because of fait accompli effect of NICE guidelines [13]. Another multicentre survey of British midwives showed similar finding (unpublished data). Many senior British Obstetricians and midwives have observed that CTG interpretation may have become "dysfunctional" in the last few years with many benign decelerations (previously termed "early") being increasingly termed "variable" and then "atypical”, making CTGs pathological. To investigate this concern, a study of interpretation of FHR decelerations was undertaken. It is important to note that all classifications of FHR decelerations are not based on level 1, 2 or 3 evidence but on expert opinion only. Hence, these should stand the test of clinical observation, rationality and logical reasoning to be considered valid. This paper encourages a debate which is expected to enhance quality of care and improve patient safety in this very important area.

\section{STUDY OF INTERPRETATION OF FHR DECELERATIONS}

\section{Methods}

A prospective observational multicentre study was conducted to compare interpretation by Consultant Obstetricians, Registrars and midwives of five definitive CTG traces given by the three British expert groups [1-3] to explain and illustrate their descriptions of FHR decelerations in training materials, in line with NICE (2007) guidelines [4]. The monogram "Fetal monitoring in practice” by Gibb and Arulkumaran (2008) is a widely accepted British reference book [3]. K2 Fetal Monitoring Training System, Plymouth (K2MS) pioneered the web based CTG training breaking new grounds and setting very high standards [2]. Their model has been emulated by many others around the world. It quite rightly remains popular with many Obstetricians and midwives. However, K2MS had to change its illustrations and descriptions of FHR decelerations to comply with NICE (2007) guidelines. The RCOG launched eFM (2011), its official award winning on-line CTG training module incorporating NICE guidelines [1,4]. The 5 experts' CTG illustrations included in the study are shown in Figures 1-4 except for illustration 4 namely "early FHR decelerations by eFM [1] (Chapter-CTG changes caused by hypoxia, part 1, page 13/26)". Permission to reproduce this illustration 4 was not obtainable, hence readers are referred to the original source. Although these illustrations have been a part of training manuals for a few years, it is important to note that web-based (on-line) materials could change in future.

Illustrations of early and late decelerations were particularly chosen for this study because of the controversy regarding their occurrence after NICE guidelines of 2007 [4]. The participants in the study were recruited on a non-selective voluntary basis by personal contact (e.g. at scientific meetings) using an anonymous printed questionnaire after obtaining approval of the Research and Development (R\&D) committee of the author's institute. Although the selection could not have been completely random, this was not necessary or relevant in common with other reported studies [18-20]. Participants were not informed of the source of illustrations. Ethical approval was not required by the $R \& D$ committee because no known patient data was involved. Total of 123 participants (38 Consultants, 50 Obstetric Specialist Registrars and 45 midwives) from NHS hospitals in different regions of UK who agreed to participate on anonymous 


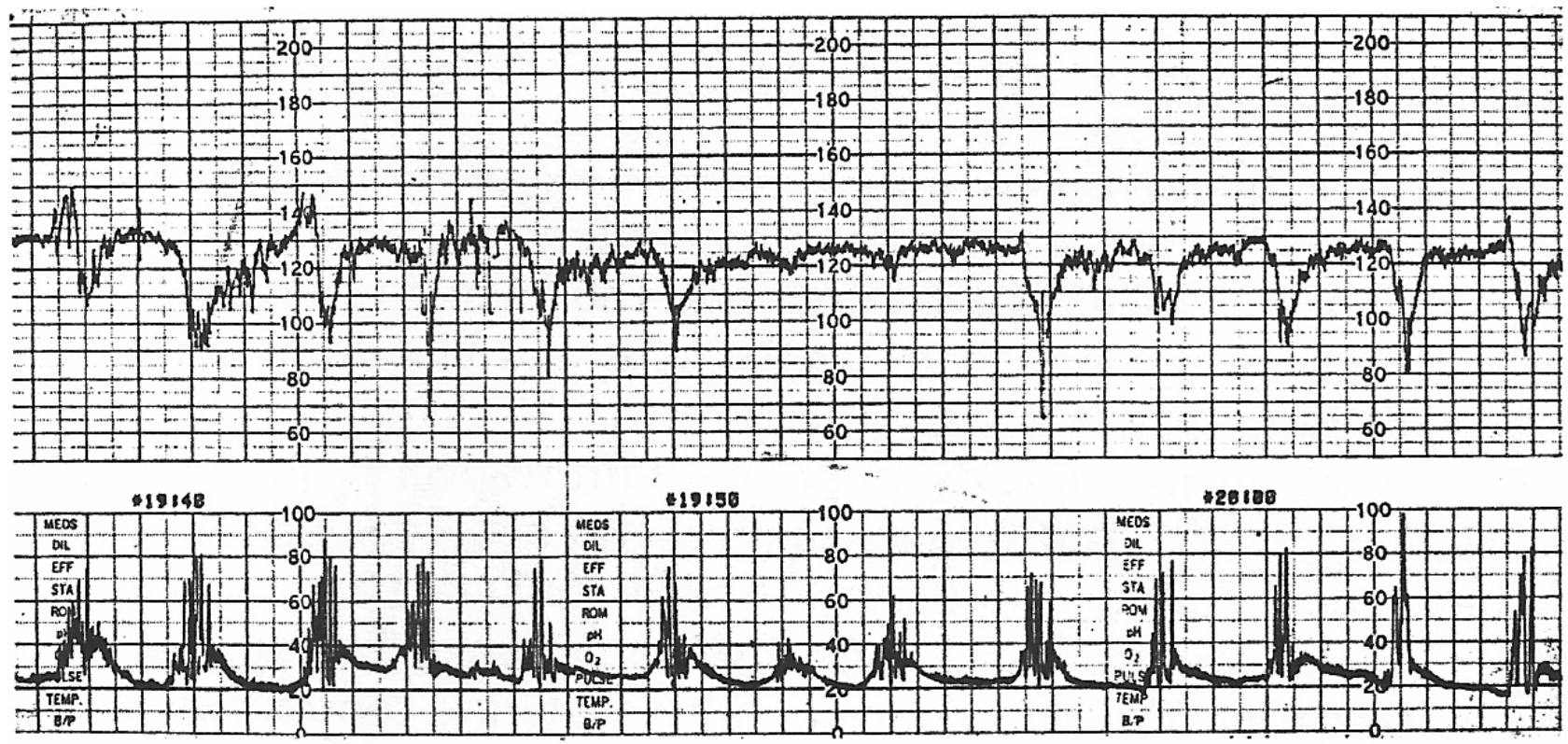

Figure 1. Study example 1: Illustration of early decelerations [3] (Reproduced with kind permission from "Fetal monitoring in practice” by Gibb and Arulkumaran, 2007, Churchill Livingstone Elsevier). CTG recording paper speed $1 \mathrm{~cm} / \mathrm{min}$.

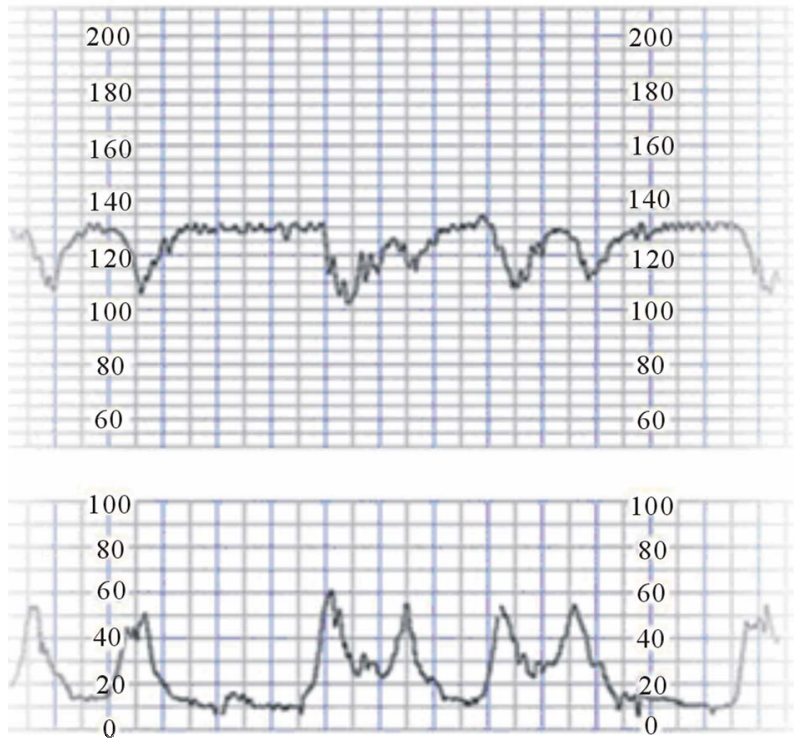

Figure 2. Study example 2: Illustration of early FHR decelerations by K2MS Fetal Monitoring Training system [2] (reproduced with kind permission from K2MS, Plymouth, UK)). British CTG recording paper speed $1 \mathrm{~cm} / \mathrm{min}$.

basis were asked to interpret five CTG illustrations (Figures 1-4) based strictly on the current NICE guidelines [4]. The images of CTG illustrations were resized (enlarged) proportionately where required to match the actual size used in clinical practice. In case of short (10 minutes) CTGs, the participants were asked to assume repetition of the same pattern for 30 minutes or more required for 3 tier classification. The participants were asked to categorize FHR decelerations into "early/late/
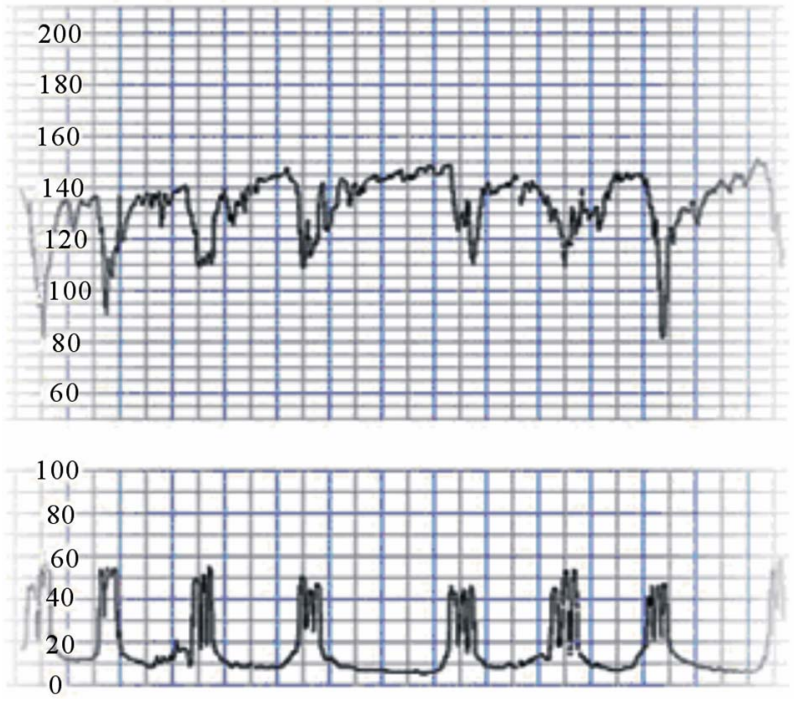

Figure 3. Study example 3: Illustration of typical variable FHR decelerations by K2MS Fetal Monitoring Training System [2] (Reproduced with kind permission from K2MS, Plymouth, UK). CTG recording paper speed $1 \mathrm{~cm} / \mathrm{min}$.

typical variable/atypical variable/no definite decelera tions”; and to classify a 30 minute CTG pattern into nor$\mathrm{mal} /$ suspicious/pathological tier based on NICE guidelines [4]. Space was provided for additional voluntary comments. The Obstetric Registrars and midwives had undergone regular CTG training by NICE approved trainers at intervals of about every 6 months on many occasions. All participants were certified to be competent in EFM. In fact the majority of CTGs are interpreted by registrars and midwives in actual practice. The results and any 

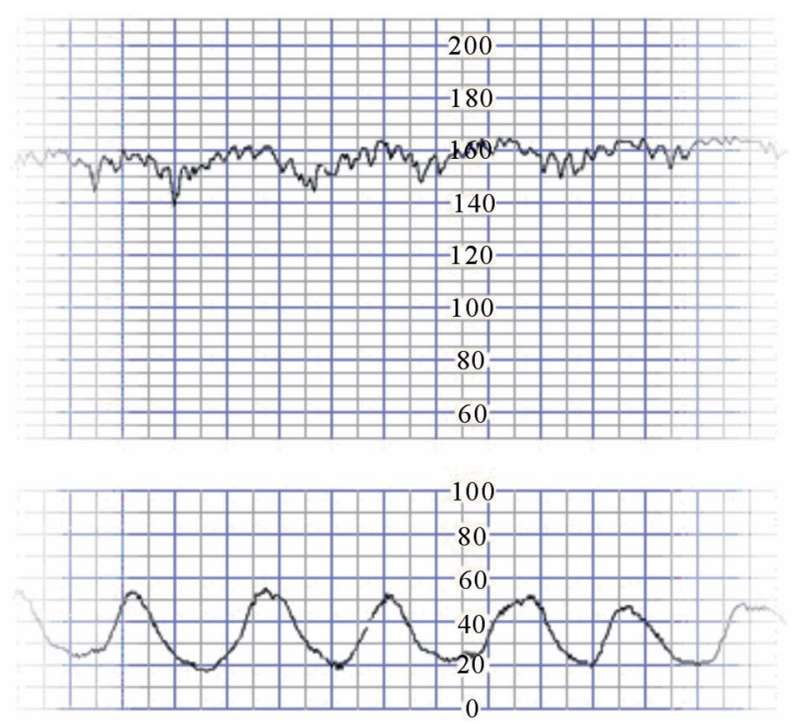

Figure 4. Study example 5: Illustration of late decelerations by K2MS Fetal Monitoring Training System [2] (Reproduced with kind permission from K2MS, Plymouth, UK). CTG paper speed $1 \mathrm{~cm} / \mathrm{min}$.

discrepancies were analyzed to explore the underlying reasons including participant factors (interobserver variation, training issues etc) and any intrinsic systemic issues with the categorization of FHR decelerations. Cochrane recommended Fisher's Exact test was used to check the statistical significance of any differences.

\section{RESULTS}

Detailed results are shown in Tables $\mathbf{1}$ and 2. In this paper the experts' illustration of different types FHR decelerations will be used synonymously as "expert interpretation". One Registrar had to be excluded from study because of incomplete answers leaving a total of 122 participants. Results revealed unbelievably high disagreement between participants and expert groups. It was observed that $98 \%-100 \%$ midwives, $80 \%$ - 100\% Registrars and 74\% - 100\% Consultants categorized FHR decelerations differently from the expert interpretation of 5 illustrations $(\mathrm{p}<0.0001)$. On the other hand midwives were very consistent in their interpretation of type of FHR decelerations with 98\% - 100\% agreeing with each other for illustrations $1-4$ and $84 \%$ for illustration 5 . Registrars also showed high degree of consistency with $65 \%$ - 86\% mutual agreement for illustrations 1-4 and $53 \%$ for illustration 5 . Consultants showed more variation with $61 \%$ - $66 \%$ agreement with each other for illustrations $2-4$ and $40 \%-42 \%$ for illustrations 1 and 5; which was still much higher than their agreement with the experts $(0 \%-26 \%)$.

NICE guidelines [4] are unclear about the place of early decelerations in the 3 tier classification. However, NICE does specify that early decelerations are "benign and not significant” (i.e. not a non-reassuring feature); hence the CTG could be called "normal". Alternative opinion could be that early decelerations should be classed into the "suspicious" tier. In either case there was significant disparity between experts and study participants. The over-whelming majority of participants $(98 \%$ $100 \%$ midwives, $65 \%$ - 86\% Registrars and $40 \%-66 \%$ Consultants) classed illustrations 1, 2 and 4 of supposeedly very benign early decelerations as "atypical variable" and hence into pathological tier. It seems reasonable to construe that expert teaching examples of early, typical variable and late decelerations would fall in normal, suspicious and pathological tiers respectively in the 3 tier classification of NICE [4] when same pattern was presumed to persist for 30 minutes or more. However, a different assumption would not materially change the finding of major disagreement seen in Table 2. The participants showed somewhat lower congruence with each other for the 3 tier classification of the illustrations (Midwives 62\% - 98\%, registrars $44 \%-82 \%$ and Consultants 52\% - 87\%) but this was still significantly higher than their agreement with expert interpretation $(0 \%-$ $52 \%)$.

\section{DISCUSSION}

There have been a few studies reporting variable interobserver interpretation of intrapartum CTG traces but generally a moderate agreement [18-20]. A multinational European study showed fair agreement among 21 obstetricians for the classification of accelerations, baseline and decelerations but poor for baseline variability [18]. Knowledge of adverse neonatal outcome lead to a more severe retrospective classification of the intrapartum CTG by five Obstetricians, derived mainly from decalerations and variability [19]. An American study of interpretation of CTG by three maternofetal specialists reported moderate interobserver agreement for categories I and II but poor for category III tracings [20]. The current study is somewhat unique and novel in that it has subjected published definitive teaching illustrations by acknowledged British experts to interpretation by a large group of trained clinicians of three different cadres. One would expect a much higher agreement (lot more than 50\%) by practicing clinicians for CTG illustrations meant to demonstrate the types of FHR decelerations for training purposes. This paper does not claim that the experts' illustrations are necessarily wrong but reports that only $0 \%$ - 26\% participants agreed with the expert interpretation which is most remarkable. It could be argued that if illustrations of "atypical variable" decelerations were chosen for the study, the agreement would have been quite high; but that would not be surprising given that the vast majority of decelerations are classed as variable (and then many atypical) by the clinicians anyway based 
Table 1. Categorization of expert illustrations of FHR decelerations based on NICE guidelines [4] by 122 study participants including 38 Consultants (Cons), 49 Obstetric Registrars (Reg) and 45 Midwives (MW). $\quad{ }^{*} \mathrm{p}<0.0001$ by Fisher’s Exact test.

\begin{tabular}{|c|c|c|c|c|c|c|c|}
\hline & \multirow{2}{*}{$\begin{array}{c}\text { Illustration of FHR } \\
\text { decelerations by } \\
\text { Experts }\end{array}$} & \multicolumn{5}{|c|}{$\begin{array}{c}\text { Interpretation of illustration (categorisation of FHR decelerations) by study participants } \\
\text { No. (\%) }\end{array}$} & \multirow{2}{*}{$\begin{array}{c}\begin{array}{c}\text { Disagreement with } \\
\text { expert }\end{array} \\
\text { categorisation No. } \\
\quad(\%) \\
{ }^{*} \mathrm{P}<0.0001\end{array}$} \\
\hline & & $\begin{array}{c}\text { Early } \\
\text { decelerations }\end{array}$ & $\begin{array}{l}\text { Typical variable } \\
\text { decelerations }\end{array}$ & $\begin{array}{c}\text { Atypical } \\
\text { variable } \\
\text { decelerations } \\
\end{array}$ & $\begin{array}{c}\text { Late } \\
\text { decelerations }\end{array}$ & $\begin{array}{c}\text { No definite } \\
\text { decelerations }\end{array}$ & \\
\hline 1 & $\begin{array}{c}\text { Early FHR } \\
\text { decelerations by Gibb } \\
\text { and Arulkumaran } \\
\text { [3] (Figure 1) }\end{array}$ & $\begin{array}{c}9(24 \%) \text { Cons } \\
5(10 \%) \text { Reg } \\
0(0 \%) M W\end{array}$ & $\begin{array}{c}14 \text { (37\%) Cons } \\
11(22 \%) \text { Reg } \\
0(0 \%) M W\end{array}$ & $\begin{array}{l}15(40 \%) \text { Cons } \\
32(65 \%) \text { Reg } \\
45(100 \%) M W\end{array}$ & $\begin{array}{c}0(0 \%) \text { Cons } \\
1(3 \%) \text { Reg } \\
0(0 \%) M W\end{array}$ & $\begin{array}{c}0(0 \%) \text { Cons } \\
0(0 \%) \text { Reg } \\
0(0 \%) M W\end{array}$ & $\begin{array}{l}29(76 \%) \text { Cons }^{*} \\
44(90 \%) \operatorname{Reg}^{*} \\
45(100 \%) \mathrm{MW}^{*}\end{array}$ \\
\hline 2 & $\begin{array}{c}\text { Early FHR } \\
\text { decelerations by } \\
\text { K2M.S [2] (Figure 2) }\end{array}$ & $\begin{array}{c}0(0 \%) \text { Cons } \\
1(2 \%) \text { Reg } \\
1(2 \%) M W\end{array}$ & $\begin{array}{l}2(3 \%) \text { Cons } \\
2(4 \%) \operatorname{Reg} \\
0(0 \%) M W\end{array}$ & $\begin{array}{l}23(61 \%) \text { Cons } \\
41(84 \%) \text { Reg } \\
44(100 \%) M W\end{array}$ & $\begin{array}{c}13(34 \%) \text { Cons } \\
5(10 \%) \text { Reg } \\
0(0 \%) M W\end{array}$ & $\begin{array}{c}0(0 \%) \text { Cons } \\
0(0 \%) \text { Reg } \\
0(0 \%) M W\end{array}$ & $\begin{array}{c}38(100 \%) \text { Cons }^{*} \\
48(98 \%) \text { Reg }^{*} \\
44(98 \%) \mathrm{MW}^{*}\end{array}$ \\
\hline 3 & $\begin{array}{c}\text { Typical variable FHR } \\
\text { decelerations by K2 } \\
\text { MS [2] } \\
\text { (Figure 3) }\end{array}$ & $\begin{array}{c}4(11 \%) \text { Cons } \\
3(6 \%) \text { Reg } \\
0(0 \%) M W\end{array}$ & $\begin{array}{c}8(21 \%) \text { Cons } \\
1(3 \%) \text { Reg } \\
0(0 \%) M W\end{array}$ & $\begin{array}{c}24(63 \%) \text { Cons } \\
41(84 \%) \text { Reg } \\
45(100 \%) M W\end{array}$ & $\begin{array}{l}2(5 \%) \text { Cons } \\
2(4 \%) \text { Reg } \\
0(0 \%) M W\end{array}$ & $\begin{array}{c}0(0 \%) \text { Cons } \\
0(0 \%) \operatorname{Reg} \\
0(0 \%) M W\end{array}$ & $\begin{array}{c}30(79 \%) \text { Cons * } \\
48(97 \%) \text { Reg* }^{*} \\
45(100 \%) M W^{*}\end{array}$ \\
\hline 4 & $\begin{array}{c}\text { Early FHR } \\
\text { decelerations by eFM } \\
{[1]}\end{array}$ & $\begin{array}{c}0(0 \%) \text { Cons } \\
0(0 \%) \text { Reg } \\
0(0 \%) M W\end{array}$ & $\begin{array}{c}2(5 \%) \text { Cons } \\
3(6 \%) \text { Reg } \\
0(0 \%) M W\end{array}$ & $\begin{array}{c}25(66 \%) \text { Cons } \\
42(86 \%) \text { Reg } \\
44(98 \%) M W\end{array}$ & $\begin{array}{c}11 \text { (29\%) Cons } \\
3(6 \%) \text { Reg } \\
0(0 \%) M W\end{array}$ & $\begin{array}{c}0(0 \%) \text { Cons } \\
1(2 \%) \text { Reg } \\
0(0 \%) M W\end{array}$ & $\begin{array}{l}38(100 \%) \text { Cons }^{*} \\
49(100 \%) \text { Reg }^{*} \\
44(98 \%) \mathrm{MW}^{*} \\
\text { 1MW (Not sure) }\end{array}$ \\
\hline 5 & $\begin{array}{c}\text { Late FHR } \\
\text { decelerations by } \\
\text { K2MS [2] (Figure 4) }\end{array}$ & $\begin{array}{c}1(3 \%) \text { Cons } \\
0(0 \%) \text { Reg } \\
0(0 \%) M W\end{array}$ & $\begin{array}{c}0(0 \%) \text { Cons } \\
1(2 \%) \text { Reg } \\
0(0 \%) M W\end{array}$ & $\begin{array}{c}11(29 \%) \text { Cons } \\
12(25 \%) \text { Reg } \\
6(14 \%) M W\end{array}$ & $\begin{array}{c}10(26 \%) \text { Cons } \\
10(20 \%) \text { Reg } \\
1(2 \%) M W\end{array}$ & $\begin{array}{l}16(42 \%) \text { Cons } \\
26(53 \%) \text { Reg } \\
38(84 \%) M W\end{array}$ & $\begin{array}{l}28(74 \%) \text { Cons }^{*} \\
39(80 \%) \operatorname{Reg}^{*} \\
44(98 \%) \mathrm{MW}^{*}\end{array}$ \\
\hline
\end{tabular}

Table 2. Three tier classification based on NICE guidelines [4] of expert CTG illustrations by 122 study participants including 38 Consultants (Cons), 49 Obstetric Registrars (Reg) \& 45 Midwives ( $M W$ ).

${ }^{*} \mathrm{p}<0.0001$ by Fisher's Exact test \# See text in "results" section for clarification.

\begin{tabular}{|c|c|c|c|c|c|}
\hline & \multirow{2}{*}{$\begin{array}{c}\text { Experts' illustration and } \\
\text { interpretation } \\
\text { (Expected } 3 \text { Tier classification } \\
\text { of a } 30 \text { minute CTG) }\end{array}$} & \multicolumn{4}{|c|}{$\begin{array}{l}\text { Three Tier classification of experts' illustrations ( } 30 \text { minute CTG pattern) by study participants } \\
\text { No. }(\%)\end{array}$} \\
\hline & & Normal & Suspicious & Pathological & $\begin{array}{l}\text { Disagreement with } \\
\text { experts }(\%) \\
{ }^{*} p<0.0001\end{array}$ \\
\hline 1 & $\begin{array}{c}\text { Early FHR decelerations by } \\
\text { Gibb and Arulkumaran [3] } \\
\text { (Figure 1) } \\
\text { (Normal) }\end{array}$ & $\begin{array}{l}3(8 \%) \text { Cons } \\
7(14 \%) \text { Reg } \\
0(0 \%) M W\end{array}$ & $\begin{array}{c}23(61 \%) \text { Cons } \\
14(29 \%) \text { Reg } \\
4(9 \%) M W\end{array}$ & $\begin{array}{l}12(31 \%) \text { Cons } \\
28(57 \%) \text { Reg } \\
41(91 \%) M W\end{array}$ & $\begin{array}{l}35(92 \%) \text { Cons }^{*} \\
42(86 \%) \text { Reg }^{*} \\
45(100 \%) M W^{*}\end{array}$ \\
\hline 2 & $\begin{array}{c}\text { Early FHR decelerations by K2 } \\
\text { M.S [2] (Figure 2) } \\
\text { (Normal) }\end{array}$ & $\begin{array}{l}1(3 \%) \text { Cons } \\
0(0 \%) \text { Reg } \\
0(0 \%) M W\end{array}$ & $\begin{array}{l}8(21 \%) \text { Cons } \\
5(10 \%) \text { Reg } \\
2(4 \%) M W\end{array}$ & $\begin{array}{l}29 \text { (76\%) Cons } \\
44(90 \%) \text { Reg } \\
43(96 \%) M W\end{array}$ & $\begin{array}{l}37(97 \%) \text { Cons }^{*} \\
49(100 \%) \text { Reg }^{*} \\
45(100 \%) \text { MW }^{*}\end{array}$ \\
\hline 3 & $\begin{array}{c}\text { Typical variable FHR } \\
\text { decelerations by K2 MS [2] } \\
\text { (Figure 3) (Suspicious) }\end{array}$ & $\begin{array}{l}3(8 \%) \text { Cons } \\
0(0 \%) \text { Reg } \\
0(0 \%) M W\end{array}$ & $\begin{array}{c}13 \text { (34\%) Cons } \\
9(18 \%) \text { Reg } \\
1(2 \%) M W\end{array}$ & $\begin{array}{l}22(58 \%) \text { Cons } \\
40(82 \%) \text { Reg } \\
44(98 \%) M W\end{array}$ & $\begin{array}{l}25(66 \%) \text { Cons }^{*} \\
40(82 \%) \text { Reg }^{*} \\
44(98 \%) \mathrm{MW}^{*}\end{array}$ \\
\hline 4 & $\begin{array}{c}\text { Early FHR decelerations by } \\
\text { eFM [1] } \\
\text { (Normal) }\end{array}$ & $\begin{array}{l}0(\%) \text { Cons } \\
2(4 \%) \text { Reg } \\
0(\%) M W\end{array}$ & $\begin{array}{l}5 \text { (13\%) Cons } \\
7(14 \%) \text { Reg } \\
3(7 \%) M W\end{array}$ & $\begin{array}{l}33(87 \%) \text { Cons } \\
40(82 \%) \text { Reg } \\
42(93 \%) \text { MW }\end{array}$ & $\begin{array}{c}38(100 \%) \text { Cons }^{*} \\
47(96 \%) \text { Reg }^{*} \\
45(100 \%) M W^{*}\end{array}$ \\
\hline 5 & $\begin{array}{c}\text { Late FHR decelerations by } \\
\text { K2MS [2] (Figure 4) } \\
\text { (Pathological) }\end{array}$ & $\begin{array}{l}9(24 \%) \text { Cons } \\
13(26 \%) \text { Reg } \\
28(62 \%) M W\end{array}$ & $\begin{array}{l}9 \text { (24\%) Cons } \\
14(29 \%) \text { Reg } \\
13(29 \%) M W\end{array}$ & $\begin{array}{c}20 \text { (52\%) Cons } \\
22(45 \%) \text { Reg } \\
4(9 \%) M W\end{array}$ & $\begin{array}{l}18(48 \%) \text { Cons }^{*} \\
27(55 \%) \text { Reg }^{*} \\
41(91 \%) M W^{*}\end{array}$ \\
\hline
\end{tabular}

on the NICE guidelines [4]. Thus the validity of the current system of categorization of decelerations is best examined by focusing on early and late decelerations. It is clearly very vital to have a debate on the reasons for the remarkable finding of this study to improve the patient safety and quality of care. The paper presents some analytical explanation and remedies but other explanations cannot be ruled out and are open to debate and the 
readers can draw their own conclusions.

The results were analyzed to look for "participant factors". The discrepancy between experts and participants did not appear to be "a (inadequate or inconsistent) training issue" because it applied to Consultants as well and there did not seem to be a regional variation. Moreover the Registrars, midwives and Consultants were intensively trained at least once a year on many occasions and certified to be competent. They were recruited from different regions of UK and had been following the same standard guidelines for 5 years or so. Moreover, there was very good agreement amongst the participants themselves. Participants varied a bit more for the 3 tier classification of the illustrations which may have been because of quite complex and confusing rules about significance of frequency, proportion and duration of subtypes of variable decelerations. Importantly the interpretation by the participants could be explained by logical reasoning. In the absence of "participant factors" it became necessary to critically look for any intrinsic reasons within the experts' illustrations themselves. It also seems simplistic to assume that the reason for high disagreement may simply be an oversight or inadvertent lack of attention to detail by the expert groups. The following in depth analysis suggests that any inaccuracies in experts' illustrations may be "enforced errors" stemming from more fundamental systemic flaws in the current categorization/definitions of FHR decelerations in the NICE guidelines [4]. These flaws seem to make it almost impossible to provide valid examples early and late decelerations and manifest as substantial heterogeneity of expert description particularly inconsistent emphasis on debatable attributes like "uniform", "repetitive" and rapid/gradual/ bell shape etc.

\subsection{Bias, Confounding, Other Reasons for Caution and Generalisability}

Based on the additional comments, midwives and Obstetric Registrars appeared to rigorously follow teaching of NICE guidelines. However, Consultants often use more flexibility and discretion in their practice based on their previous experience (put old hat on) and personal views. However, all participants were asked to interpret illustrations based strictly on NICE guidelines only [4]. Very high (98\% - 100\%) disagreement by midwives may have been because of preponderance of hospitals where midwives were taught and instructed not to class any FHR decelerations as "early" or "late" because no decelerations are truly uniform, a strange notion indeed. The results of the 3 tier classification are more subjective. Since, NICE guidelines have been universally adopted in the UK, the results of this study would be very highly generalisable. Moreover, analytical conclusions of this study would be applicable to other national guidelines with a possibility of achiev- ing meaningful uniformity of EFM guidelines in North America, Europe and Australasia, critical for future research and progress in this very important field.

\subsection{British (RCOG, 2001; NICE, 2007) Definitions of FHR Decelerations [4,17]}

The importance of standardized and unambiguous definitions has been well documented [14-16]. The British definitions were described in RCOG guidelines of 2001 [17] and were adopted by NICE in 2007 [4]; but are not accessible on-line at present.

Early decelerations: "Uniform, repetitive, periodic slowing of FHR with onset early in the contraction and return to baseline at the end of the contraction".

Late decelerations: "Uniform, repetitive, periodic slowing of FHR with onset mid to end of the contraction and nadir more than 20 seconds after the peak of the contraction and ending after the contraction.

Variable decelerations: "Variable, intermittent periodic slowing of FHR with rapid onset and recovery. Time relationships with contraction cycle are variable and they may occur in isolation. Sometimes they resemble other types of deceleration patterns in timing and shape."

It needs to be debated whether RCOG/NICE definitions (adopted from description by Edward Hon [21], personal correspondence with NICE) are unambiguous. Hon et al (1968) described early and late decelerations to have a "uniform pattern" of a specific time relationship to contraction cycle [21]. However, quoted without proper context, the term "uniform" in RCOG definition has been misinterpreted as identical i.e. "uniform in duration and depth and shape" (a biological implausibility) even by expert groups like eFM of RCOG and NICE [1,4]. The first sentence in the RCOG definition of "variable" decelerations specifies rapid onset (descent) hence this may be construed as the main characteristic. By corollary "early" and "late" decelerations may be required to have "gradual" descent but this has not been specified in their definitions. The second sentence in the definition of "variable" definition corresponds to traditional British definition [22-25] in that the time relationships to contraction cycle must be variable. The last sentence in the definition of variable decelerations appears an "abstraction" because not only it contradicts the first two sentences, but based on it any decelerations could be justifiably called "variable”!

\subsection{Heterogeneity of British Expert and NICE Descriptions of FHR Decelerations}

NICE (2007) categorically states that early decelerations are "truly uniform" and there is a mention of rapid descent for variable decelerations in RCOG definitions $[4,17]$. It is difficult to imagine any other meaning of 
"truly uniform" apart from "same in depth and duration i.e. identical”. RCOG experts (eFM, CTG changes caused by hypoxia, part 1, pages 13-14/26) have indeed confirmed this by specifying that early and late decelerations must be uniform in both length and depth, but without mentioning gradual shape [1]. Gibb and Arulkumaran (2008) described of "early" decelerations to be "bell" (gradual) shaped without mentioning "uniform" shape [3]. K2MS experts (Chapter-Decelerations, page 14/21) state "Early decelerations are uniform in shape, have rounded nadir (U shaped) and have symmetry with contractions". But it is unclear what K2MS experts mean by uniform. Thus it can be surmised that the three British expert and NICE/RCOG descriptions of different FHR decelerations vary significantly. None appear standardized, comprehensive or unambiguous.

Table 1 shows that 77\% Consultants, 87\% SpRs and $100 \%$ midwives categorized illustration 1 of early decalerations by Gibb and Arulkumaran [3] as "variable" because of different sizes and deep " $V$ " shape. 75\% participants further classed majority decelerations as "atypical" because of lack of shoulders, possibly making the CTG "pathological". These decelerations do not fulfil "bell or gradual” shaped description by Gibb and Arulkumaran themselves. However, they would be classed as early based on traditional British practice before 2007 [22-25] (Figure 5). Thus a definitive example of most benign

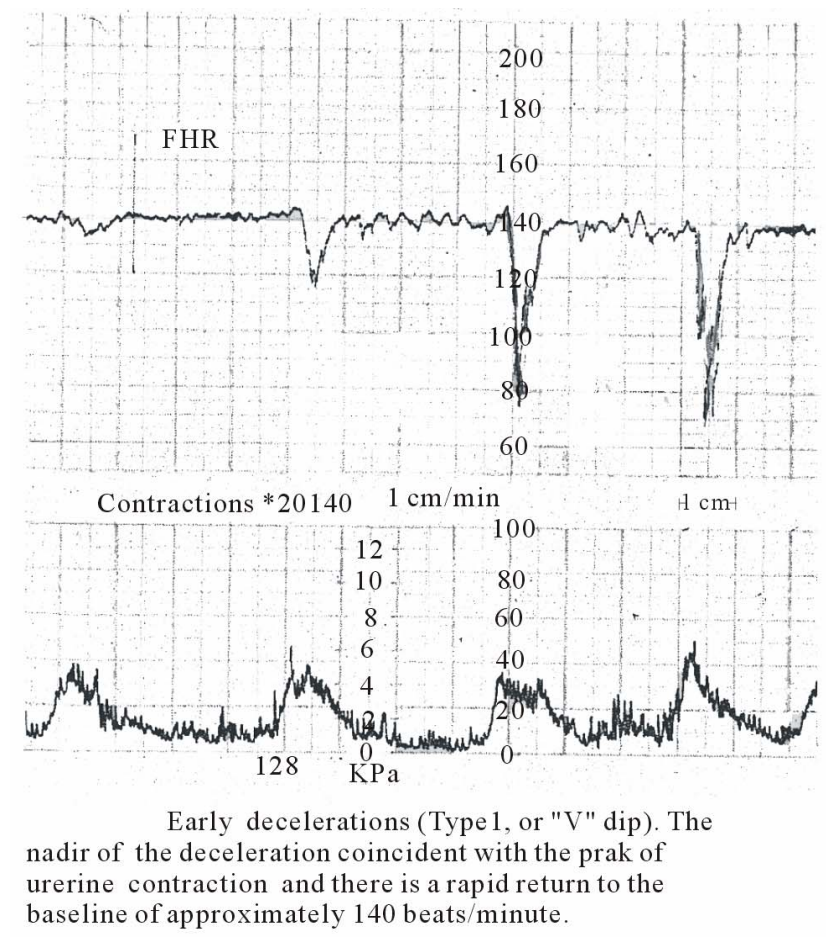

FHR decelerations (early) was classed as "pathological” by $66 \%$ of Obstetricians and midwives (Table 2) based on their current mandatory CTG training. It appears that in order to give example of hypothetical and elusive ' $U$ ' shaped (gradual) early decelerations, K2MS experts may have inadvertently shown somewhat shallow decelerations with late time relationship to contractions in illustration 2 . The vast majority of participants (89\%) categorized illustration 3 decelerations as "atypical variable" and CTG as "pathological" (Tables 1-2). The reason quite correctly seems to be absence of shoulders (initial small accelerations). It is relatively common for shoulders to be absent. The positive predictability of "atypical" features has never been tested in a British study. RCOG adopted the definitions of atypical variable decelerations from American authors Krebs et al who reported that the "loss of initial acceleration" was the commonest atypical feature but was also found to be quite benign [26]. The only good quality evidence (level IIA) available subsequently has refuted and invalidated the significance of "atypical features". An important study of 5388 deliveries by Cahill et al. (2012) reported no correlation between "atypical features" and incidence of neonatal acidemia [6]. Hamilton et al. [7] analyzed digital EFM tracings of 3695 patients specifically testing the 6 atypical features described by the RCOG. They found that only one feature namely "loss of variability during a

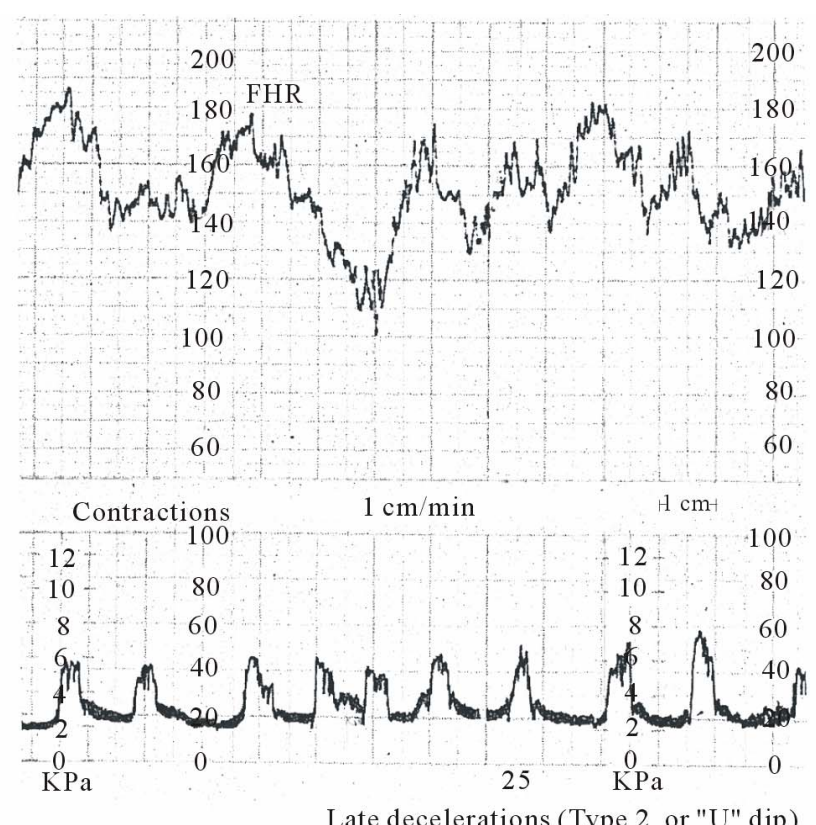

Late decelerations (Type 2, or "U" dip).

There is a baseline tachycardia. Decelerations of longer duration than with Type 1 dips and continue after the contraction has passed.

Figure 5. Early and late decelerations in traditional British practice (Reproduced with kind permission from "Principles of Obstetrics” by Bryan Hibbard, 1988) [25]. Note apparent rapid rather than gradual descent of FHR decelerations. Late decelerations are described as "U" shaped only in comparison to "V" shaped early decelerations. Other British authorities gave very similar descriptions and illustrations [22-24]. Paper speed $1 \mathrm{~cm} / \mathrm{min}$. 
deceleration" correlated to neonatal acidemia better than chance alone. However, this feature cannot be reliably interpreted for vast majority of short lasting decelerations on the British CTG because of slower paper speed. American Congress of Obstetricians and Gynecologists (ACOG) does not subdivide variable decelerations into “typical” and "atypical” [12]. Most participants (95\%) interpreted illustration 4 of early decelerations by eFM [1] as "variable” and then "atypical” thus classifying CTG as pathological (94\%).

The majority of participants (66\%) interpreted illutration 5 of late decelerations by K2MS [2] (Figure 4) as "no definite decelerations" because FHR drops were less than 15 bpm, not significant, given the good baseline variability. This teaching illustration (equivocal at best) appears to be an inadvertent or enforced error by K2MS experts because of the focus on complying with the "gradual" attribute of the late decelerations which is unrealistic on British CTG (paper speed $1 \mathrm{~cm} / \mathrm{min}$ ) as described below.

\subsection{Gradual/U/Bell Shape, Uniform and Repetitive}

A particular defining feature has been gradual or " $U$ " or "bell" shape of early decelerations which makes them almost impossible to find on British CTG despite being thought to be because of a very common event of head compression. The concept comes from North American practice and seems to be based on an unsubstantiated hypothesis that because the recorded contraction curves appear "gradual", the decelerations due to head compression must be gradual [13]. However, many American authorities have reported that head compression is the likely cause of many rapid decelerations classed currently as "variable" [28-32]. Studies by the group of Caldeyro-Barcia, Rech, Chung and Hon demonstrated that bimanual transabdominal as well as vaginal compressions of fetal head resulted in rapid FHR decelerations [30-32]. Moreover, FHR decelerations which appear "gradual" on the American CTG (paper speed $3 \mathrm{~cm} / \mathrm{min}$ ) will appear "rapid" on the British CTG (paper speed $1 \mathrm{~cm} / \mathrm{min}$ ). Lastly, because of the physical scales of British CTG, only very shallow decelerations will look gradual or bell shaped. For example there is no reason why head compression during contraction could not cause a deceleration of depth $30 \mathrm{bpm}$ lasting for 30 seconds but that will have a "horizontal: vertical" dimension ratio of $1: 3$ on British CTG and will not look gradual (function or effect of scale, nothing to do with etiology or fetal condition). Hence it is no surprise that contrary to current definitions, many mainstream British authors [22-25] previously quite rightly described and depicted "early" decelerations to have "V" shape (rapid), although the shape was not the main defining feature (Figure 5). Thus it seems reasonable to conclude that the concept of "early" decelerations being "gradual” or "bell” shaped is erroneous and best discarded. In contrast to NICE guidelines but based on traditional British teaching and practice [22-25] (Figure 5), FHR deceleration in illustration 1 and 3 could be classed as "early" (occurring during contractions and consistent with pure vagal reflex due to head compression) and hence completely benign. This explains an observation that FHR decelerations previously classed as completely benign are increasingly being categorized as "pathological" because of soft unreliable disproven markers like absence of shoulders [5-7,26]. This may be potentially harmful because it is likely to increase intervention and also impair the ability to identify the smaller subset of truly pathological decelerations and act on them. A particular hazard is that quite markedly pathological late decelerations get classed as "variable”, leading to perilous procrastination and prevarication before eventually being recognized as atypical or pathological (amongst the vast number of other "false alarm" atypical ones). Many Obstetricians have been recently concerned that there may be rising incidence of severe birth asphyxia due to possible increasing misinterpretation of CTG. Repeated false alarms have been described to be deleterious because they create frustration with the technique and cause alarm-fatigue that can lead to tracing disregard even when the tracing is quite abnormal [7].

Nice (2007) and RCOG (eFM) require early and late decelerations to be "truly uniform" [1,4]. Hon and Quilligan (1968) used the term "uniform" somewhat loosely to mean "specific FHR pattern" with a particular time relationship to contractions. The term "uniform" in the Hon's definition should not be used as it has been misinterpreted by clinicians and even by experts [1,4]. If FHR decelerations follow a particular uniform rule, then that rule should be specified rather than using the term itself. That uniform rule or pattern seems to be the "time relationship to contractions" which is already an integral part of the definition. There is no pathophysiological basis for any FHR decelerations to be "truly uniform or identical" but on the contrary some variation in size is the biological rule. "Truly uniform” (identical in width and depth) decelerations as proposed by NICE [4] and eFM experts [1] do not occur (a biological implausibility) and hence a myth. This myth may lead to extinction of the most benign (early) group of decelerations which is already happening. It should be debated if it is acceptable to base scientific definitions and practice on myths.

It may also be debated if another seemingly attractive term (roughly) "symmetrical”, although relatively benign, is helpful in classification of decelerations in any meaningful way. The common short lasting decelerations 
during contractions are roughly symmetrical any way. Late decelerations when have prolonged recovery time than descent (hence somewhat asymmetrical) are in fact likely to have worse prognosis.

The term "repetitive" has been misinterpreted by many British CTG trainers as "occurring with every contraction without fail" which has no scientific basis. All contractions are not the same and some thresholds for decelerations may not be met during every contraction. Hence early decelerations need not occur with every contraction. Thus the ambiguous term "repetitive" should be explained or best replaced by "recurrent" which by expert consensus means "associated with more than 50\% of contractions" [14].

\subsection{Rapid Descent of FHR, Cord Compression Hypothesis and Baroreceptor Mechanism}

Readers are referred to a similarly titled paragraph in an open access peer reviewed publication [33] (http://www. scirp.org/journal/ojog) for a detailed discussion and an informative diagram of major contradictions and fallacies with the cord compression hypothesis and baroreceptor mechanism. Theoretical hypothesis modeling as well as consistent evidence from many animal experiments proves that cord compression cannot explain the "apparent” rapid FHR decelerations during contractions with the trough of deceleration corresponding to the peak of contraction [33]. These rapid decelerations during contractions seem consistent with "direct" or "pure" vagal reflex, commonest cause being head compression (and possibly multifactorial) as indeed proposed by many British authors [22-25] and hence seem to be best classed as early decelerations. Moreover, the placenta being a large soft organ is more likely to be compressed than the umbilical cord especially in presence of reduced liquor. This (placental compression theory) will result in blood flowing from placenta to the fetus during contraction phase and vice versa during relaxation phase, causing benign decelerations with trough corresponding to peak of contraction [13]. The small accelerations before and after the "rapid" FHR drops need not be a result of umbilical venous followed by arterial occlusion (a flawed hypothesis) but may simply reflect interplay of sympathetic and parasympathetic neuronal influences similar to baseline variability [13].

\subsection{Intermittent Auscultation (IA) of Fetal Heart Rate in Labor}

NICE recommends 'Intermittent Auscultation (AI) of FHR' in low risk women [4]. There is no recommendation or need to auscultate FHR during uterine contractions because all decelerations occurring during contractions are almost always benign and hence were previ- ously defined as "early". If vast majority of decelerations in labor (most occur during contractions) are deemed "variable" to be further differentiated into "typical" and "atypical (pathological)", then IA will need to be performed during contractions as well. Women with decelerations heard during contractions will then need continuous CTG. Thus the flaws in current RCOG/NICE definitions of FHR decelerations seem to create a conflict with philosophy and practice of IA [4,17].

\subsection{Implications for Future Clinical Practice- Timing or Shape?}

The etiology of FHR decelerations will always remain "putative" and is likely to be multifactorial [13]. FHR decelerations can be said to be of two main types, one due to parasympathetic (vagal) reflex and the other due to direct suppression of myocardium due to hypoxemia [2]. The clue to detect hypoxic components is in the "timing" rather than "shape". Since hypoxemia has a lag time to develop or worsen during contraction, it causes decelerations which are late in timing by combination of chemoreceptor reflex and in more severe cases direct myocardial suppression. Currently variable decelerations constitute the majority because the common rapid and "nonidentical" FHR decelerations even when consistently occurring during contractions are classed as variable. However, available British studies by Edington et al. [34] and Steer [35] and a recent opinion survey of senior Obstetricians [13] and midwives (unpublished data) show that early decelerations constituted the majority in the traditional British practice before 2007. A stance that "it does not matter how (arbitrarily) FHR decelerations are defined as long as you know what to do with them" cannot be supported. Unsound definitions of FHR decelerations will lead to wrong conclusions and actions. A classification system with "early decelerations as majority" (as expected physiologically) seems a better predictor of fetal condition although level 1 or 2 evidence for this is lacking in common with most aspects of EFM. But that may not be a justification to practise another demonstrably unscientific and flawed system based on myths. Moreover, good evidence has emerged in USA that a system with "variable" decelerations as vast majority leads to loss of information or discriminatory capacity of FHR decelerations $[5,6,9]$. The resultant dysfunction of the 3 tier system has led a group of American experts to propose a complex "algorithm" to which the vast majority $(>80 \%)$ of laboring women will be subjected in addition to the 3 tier system [36]. However, besides many unanswered questions, there is no estimate of sensitivity of this "algorithm" in picking up cases of fetal hypoxemia or acidemia and it seems to be a leap of faith or belief. An indirect measure like FHR patterns has consi- 
derable limitations to assess fetal condition. Hence, to reduce fetal hypoxic damage to bare minimum, it seems necessary to settle for high sensitivity at the expense of specificity. For this reason the positive predictive value of "pathological CTG" in British practice remains low (below 50\%) Future research should address this drawback. A supplementary test is often necessary and the current British practice recommends fetal blood sampling when vaginal delivery can be anticipated. ST analysis (STAN) has shown a limited promise [37] but a meaningful and valid conventional CTG interpretation seems a prerequisite.

\subsection{Proposed Definitions of FHR Decelerations}

A debate is required about defining FHR decelerations in a relatively unambiguous and standardized fashion. The following is a model which involves only slight modification of NICE/RCOG [4,17] definitions but with significant impact on interpretation. The ambiguous term "uniform" is unnecessary and "repetitive" is replaced by more understandable term "recurrent" (associated with more than 50\% contractions) [14]. The 20 seconds lag time for late decelerations is based on expert consensus (RCOG) [17] and seems practically useful.

Early Decelerations: Recurrent slowing of FHR with onset early in the contraction and return to baseline at the end of contraction.

Late Decelerations: Recurrent slowing of FHR with onset mid to end of contraction and nadir more than 20 seconds after peak of contraction and ending after the contraction. If baseline variability is less than 5 beats/ min, then the definition would include decelerations less than 15 beats/min.

Variable decelerations: Recurrent slowing of FHR with varying time relationship to the contraction cycle. They tend to markedly vary in shape.

Variable decelerations could be further subdivided into typical and atypical based on accepted criteria $[4,17,26]$. Loss of shoulders seems the commonest but quite benign feature [26] and may be best disregarded. "Late components described by Cibils [27] are likely to have better positive predictive value especially when applied to a smaller better defined selective group of variable decelerations.

\section{CONCLUSIONS}

A prospective observational study showed that the British experts' interpretations (five teaching illustrations of CTGs) [1-3] were not reproduced to a very large extent (74\% - 100\% disagreement) by intensively trained Obstetric Registrars, midwives and Consultants in NHS hospitals where vast majority of confinements occur. This disconnect did not appear to be because of inade- quate training or inter-observer variation amongst the participants. The main reason for this seems to be flawed emphasis on shapes of decelerations in NICE [4] guidelines resulting in confusion, several inconsistencies and heterogeneity of expert opinion. Currently the vast majority of FHR decelerations are placed in a single heterogeneous group of variable decelerations. A high proportion of these are further termed "atypical" based on disproven and invalidated criteria [5-7] making many CTGs pathological. Repeated false alarms are deleterious in two ways. They are likely to lead to excess intervenetion as well as suboptimal identification of hypoxemic babies leading to inappropriate management decisions. FHR decelerations lend themselves to a meaningful classification based on their time relationship to contractions as proposed by Hon [21] but not on shapes of waveforms (rapid, gradual, uniform) [33]. It should be debated whether the current British practice is based on two myths viz. early and late decelerations must be "truly uniform" (a misinterpretation of description by Hon) and must “appear” gradual or bell shaped. "Truly uniform” (identical) decelerations seem a biological implausibility and no examples can be found. Gradual/rapid shape of decalerations is function of scale used for display of CTG recording and cannot be correlated to putative etiology or fetal condition [13]. Both head and cord compression produce FHR decelerations with rapid descent. Only very shallow decelerations (unless longer than 60 - 90 sec) will appear "gradual” on British CTG (paper speed 1 $\mathrm{cm} / \mathrm{min}$ ). A narrative based on myths cannot be called science. Any future guidelines on electronic fetal monitoring (EFM) should specifically include standardized definitions of FHR patterns most importantly decelerations. It needs to be urgently debated whether there are fundamental flaws in current categorization of FHR decelerations and is it necessary to rectify these in the interest of patient safety and quality of care. Debate should explore whether classification of FHR decelerations based primarily on time relationship to contraction cycle [22-25] may be scientifically robust, more consistent and clinically useful. Computerized CTG interpretation systems supplementing these principles may prove clinically more useful providing multiple pattern recognition data for research. However, because of expensive medicolegal liability of missed diagnosis of fetal hypoxemia, computer programmes are unlikely to provide management decisions at least in near future.

\section{ACKNOWLEDGEMENTS}

This paper would not have been possible without the help of the institute's efficient library staff enabling prompt access to published literature. The author is grateful to all previous authors and experts contributing to the progress of electronic fetal monitoring. The author is thankful to all the participants in the study. The author greatly appreci- 
ates the effort of his Registrars and Consultants from other hospitals who recruited some of the participants. Alline Xiao of the OJOG Editorial Office and the type-setters have handled the processing of this manuscript very professionally and efficiently.

\section{REFERENCES}

[1] Fetal Heart Rate Monitoring (2011) An e-learning resource improving the interpretation of EFM in labour and its subsequent management. Department of Health Programme and Royal College of Obstetricians and Gynaecologists and the Royal College of Midwives, Lon- don.

[2] K2 Fetal Monitoring Training System (2009) K2 medical systems. Plymouth. http://www.k2ms-university.com

[3] Gibb, D. and Arulkumaran, S. (2007) Control of fetal heart rate and NICE guidelines. In: Gibb, D. and Arulkumaran, S., Eds., Fetal Monitoring in Practice, 3rd Edition, Churchill Livingstone, London, 27-44.

[4] National Collaborating Centre for Women's and Children's Health (2007) Intrpartum care-Care of healthy women and their babies during childbirth. Royal College of Obstetricians and Gynaecologists, London. http://guidance.nice.org.uk/CG55

[5] Cahill, A.G., Roehl, K.A., Odibo, A.O. and Macones, G.A. (2012) Association and prediction of neonatal acidemia. American Journal of Obstetrics and Gynecology, 207, 206.e1-206.e8.

[6] Cahill, A.G., Roehl, K.A., Odibo, A.O. and Macones, G.A. (2012) Association of atypical decelerations with acidemia. Obstetrics and Gynecology, 120, 1387-1393.

[7] Hamilton, E., Warrick, P. and O’Keeffe, D. (2012) Variable decelerations: Do size and shape matter? Journal of Maternal-Fetal Neonatal Medicine, 25, 648-653. doi:10.3109/14767058.2011.594118

[8] Parer, J.T. and Ikeda, T. (2007) A framework for standardized management of intrapartum fetal heart rate patterns. American Journal of Obstetrics and Gynecology, 197, 26.e1-26.e6.

[9] Coletta, J., Murphy, E., Rubeo, Z. and Gyamfi-Bannerman, C. (2012) The 5-tier system of assessing fetal heart rate tracings is superior to the 3-tier system in identifying fetal acidemia. American Journal of Obstetrics and Gynecology, 206, 226.e1-206.e5.

[10] NHS Litigation Authority (2011) Factsheet 3: Information on claims. NHSLA, London. http://www.nhsla.com

[11] Kmietowicz, Z. (2012) NHS in England paid out £3.1bn in compensation claims linked to maternity care in past decade. British Medical Journal, 345, e7290. doi:10.1136/bmj.e7290

[12] American College of Obstetricians and Gynecologists (2009) Intrapartum fetal heart rate monitoring: Nomenclature, interpretation and general management principles. Obstetrics and Gynecology, 114, 192-202.

[13] Sholapurkar, S.L. (2012) The conundrum of vanishing early decelerations in British obstetrics, a step backwards? Detailed appraisal of British and American classifications of fetal heart rate decelerations-Fallacies of emphasis on waveform and putative aetiology. Journal of Obstetrics and Gynaecology, 32, 505-511. doi:10.3109/01443615.2012.689029

[14] National Institute of Child Health and Human Development (NICHD) Research Planning Workshop (1997) Electronic fetal heart rate monitoring: Research guidelines for interpretation. American Journal of Obstetrics and Gynecology, 177, 1385-1390.

[15] Veltman, L. and Larison, K. (2010) P.U.R.E. (purposeful, unambiguous, respectful, and effective) Conversations and electronic fetal monitoring: Gaining consensus and collaboration. American Journal of Obstetrics and Gynecology, 203, 440.e1-440.e4.

[16] Miller, D.A. and Miller, L.A. (2012) Electronic fetal heart rate monitoring: Applying principles of patient safety. American Journal of Obstetrics and Gynecology, 206, 278-283. doi:10.1016/j.ajog.2011.08.016

[17] Royal College of Obstetricians and Gynaecologists (2001) The use of electronic fetal monitoring: The use and interpretation of cardiotocography in intrapartum fetal surveillance. Royal College of Obstetricians and Gynaecologists Press, London.

[18] Donker, D.K., van Geijn, H.P. and Hasman, A. (1993) Interobserver variation in the assessment of fetal heart rate recordings. European Journal of Obstetrics \& Gynecology and Reproductive Biology, 52, 3-8. doi:10.1016/0028-2243(93)90220-7

[19] Ayres-de-Campos, D., Arteiro, D., Costa-Santos, C. Bernardes, J. (2011) Knowledge of adverse neonatal outcome alters clinicians' interpretation of the intrapartum cardiotocograph. Obstetrics \& Gynecology, 118, 978-984. doi:10.1111/j.1471-0528.2011.03003.x

[20] Blackwell, S.C., Grobman, W.A., Antoniewicz, L., Hutchinson, M. and Gyamfi, B. C. (2011) Interobserver and intraobserver reliability of the NICHD 3-tier fetal heart rate interpretation system. American Journal of Obstetrics and Gynecology, 205, 378.e1-378.e5.

[21] Hon, E.H. and Quilligan, E.J. (1968) Electronic evaluation of fetal heart rate. IX. Further observations on "pathologic" fetal bradycardia. Clinical Obstetrics \& Gynecology, 11, 145-167. doi:10.1097/00003081-196803000-00009

[22] Ritchie, J.W.K. (1986) Fetal surveillance. In: Whitfield, C.R., Ed., Dewhurst's Textbook of Obstetrics and Gynaecology for Postgraduates, 4th Edition, Blackwell Scientific Publications, Oxford, 442-462.

[23] Williams, J. and Blanchard, J. (1996) Suspicious and pathological fetal heart traces. In: Williams, J. and Blanchard, J., Eds., Electronic Monitoring of Fetal Heart, Midwives Press, Hale, 24-42.

[24] Malvern, J. (1989) The clinical management of labour. In: Turnbull, A. and Chamberlain, G., Eds., Obstetrics, Churchill Livingstone, London, 713-723.

[25] Hibbard, B.M. (1988) Assessment of fetal condition during labour. In: Hibbard, B.M., Ed., Principles of Obstetrics, Butterworth \& Co. (Publishers) Ltd., London, 472489.

[26] Krebs, H.B., Petres, R.E. and Dunn, L.J. (1983) Intra- 
partum fetal heart rate monitoring. VIII. Atypical variable decelerations. American Journal of Obstetrics and Gynecology, 145, 297-305.

[27] Cibils, L.A. (1978) Clinical significance of fetal heart rate patterns during labor. V. Variable decelerations. American Journal of Obstetrics and Gynecology, 132, 791-805.

[28] Ball, R.H. and Parer, J.T. (1992) The physiologic mechanisms of variable decelerations. American Journal of $\mathrm{Ob}$ stetrics and Gynecology, 166, 1683-1688. doi:10.1016/0002-9378(92)91557-Q

[29] Garite, T.J. (2002) Intrapartum fetal Evaluation. In: Gabbe, S.G., Niebyl, J.R. and Simpson, J.L., Eds., Obstetrics-Normal and Problem Pregnancies, 4th Edition, Churchill Livinstone, New York, 395-429.

[30] Mendez-Bauer, C., Poseiro, J.J., Arellano-Hernandez, G., Zambrana, M.A. and Caldeyro-Barcia, R. (1963) Effects of atropine on the heart rate of the human fetus during labor. American Journal of Obstetrics and Gynecology, 85, 1033-1053.

[31] Rech, W. (1933) Untersuchungen über die Herztätigkeit des Fetus. III. Die Wirkung des Kopfdruckes auf die Frequenz des fetalen Herzchlages. Archives of Gynaecology, 154, 47-57.

[32] Chung, F. and Hon, E.H. (1959) The electronic evaluation of fetal heart rate. I. With pressure on the fetal skull. Obstetrics and Gynecology, 13, 633-640.
[33] Sholapurkar, S.L. (2013) Critical evaluation of American categorization of fetal heart rate (FHR) decelerations and three tier classification-Shortcomings, contradictions, remedies and need for debate. Open Journal of Obstetrics and Gynecology, 3, 362-370.

http://www.scirp.org/journal/ojog

[34] Edington, P.T., Sibanda, J. and Beard, R.W. (1975) Influence on clinical practice of routine intra-partum fetal monitoring. British Medical Journal, 3, 341-343. doi:10.1136/bmj.3.5979.341

[35] Steer, P.J., Little, D.J., Lewis, N.L., Kelly, M.C. and Beard, R.W. (1976) The effect of membrane rupture on fetal heart rate in induced labour. Obstetrics \& Gynecology, 83, 454-459. doi:10.1111/j.1471-0528.1976.tb00865.x

[36] Clark, S.L., Nageotte, M.P., Garite, T.J., Thomas, J., Garite, M.D., Roger, K., et al. (2013) Intrapartum management of category II fetal heart rate tracings: Towards standardization of care. American Journal of Obstetrics and Gynecology, 209, 89-97. doi:10.1016/j.ajog.2013.04.030

[37] Vayssière, C., Tsatsaris, V., Pirrello, O., Cristini, C., Arnaud, C. and Goffinet, F. (2009) Inter-observer agreement in clinical decision-making for abnormal cardiotocogram (CTG) during labour: A comparison between CTG and CTG plus STAN. Obstetrics \& Gynecology, 116, 10811087. doi:10.1111/j.1471-0528.2009.02204.x 